\title{
Development of interdisciplinary protocols on medico-legal documentation of torture: Sleep deprivation
}

\author{
Elna Søndergaard*, Rupert Skilbeck**, Efrat Shir***
}

\section{Key points of interest}

- Our experience indicates that the likelihood of ensuring accountability for perpetrators depends upon the quality of the documentation submitted to courts and investigative bodies.

- Formulating approaches to translating the medical and legal literature and knowledge about torture methods into specific interdisciplinary instruments or protocols applicable in a local context - based on which better documentation practices could be developed.

- Development of the Sleep Deprivation Protocol as the first testing of the research-based approach.
^) Senior Legal Advisor DIGNITY - Danish Institute Against Torture, and Associate Professor, Law Faculty, Copenhagen University.

$\star \star)$ Director, REDRESS.

$\star \star \star)$ Manager of Medico-Legal Documentation, Public Committee Against Torture in Israel (PCATI).

Correspondence to: es@dignity.dk

\begin{abstract}
Background: The use of psychological torture or torture methods that leave no visible marks (stealth torture) is on the increase in various contexts. However, the difficulties in the documentation of such methods should be recognized by lawyers and health professionals who may benefit from using research-based interdisciplinary instruments to improve their documentation for legal processes - in addition to the United Nations Manual on the Effective Investigation and Documentation of Torture and Other Cruel, Inhuman or Degrading Treatment or Punishment (1999) (Istanbul Protocol). Objective: With the aim to develop additional instruments for the documentation of various psychological torture methods, this article explains the recommended methodology for such research-based interdisciplinary instruments and the process of developing the first example of this approach relating to sleep deprivation. Development and pilottesting of the Sleep Deprivation Protocol: The pilot-testing of the Protocol by lawyers in the Public Committee Against Torture in Israel (PCATI) has already yielded positive results. Conclusion: Further advanced documentation instruments, using medical evidence in non-torture contexts and legal research, should be developed to effectively identify and record other psychological torture methods.
\end{abstract}


Keywords: Psychological torture, accountability, medico-legal documentation, interdisciplinary cooperation between lawyers and health professionals, sleep deprivation

\section{Introduction}

Torture and cruel, inhuman or degrading treatment or punishment ("ill-treatment") continue to be practiced widely worldwide, and the use of torture methods that leave no visible marks is on the increase in various contexts and countries (Rejali, 2007). Such methods can and will often lead to psychological long-term effects (PérezSales, 2017). The apparatus of torture, its agents as well as the deleterious impact on the victim are rendered invisible. The difficulty in assessing the consequences, documenting it legally and medically, and adjudicating cases is thus amplified when it comes to psychological torture (Cakal, 2018). Examples of psychological torture methods (used alone or together with other techniques to produce a cumulative effect) include, among others, solitary confinement, sleep deprivation, sensory deprivation, sensory overstimulation, humiliations, and threats. Many of these techniques do not have specific definitions or parameters, and it will be up to lawyers in individual cases to explain how such treatment is unlawful, or how the impact on a particular individual may cross the severity threshold to make it torture.

The forthcoming review of the Istanbul Protocol, which sets out minimum standards for legal and medical investigations of cases of alleged torture, aims to provide guidelines for national authorities to ensure the collection of evidence so that perpetrators can be held accountable for their actions. One of the standards stipulates that both a physical and a psychological assessment of the victim of torture should be undertaken (OHCHR, 2004, Chapter VI). The Istanbul Protocol provides useful guidance for health professionals and lawyers - for example regarding legal standards, interviewing techniques and general knowledge about the consequences of torture. However, the assumption is that attitude and skills with regards to documentation of psychological torture would improve further by additional research and the development of specific questions that take into consideration the complexities of the matter and existing legal and medical research.

Information collected by PCATI shows that the Israeli authorities commonly use complex techniques based on directly attacking the conscious self of victims causing pain without obvious marks (PCATI, 2016 and 2019). The Israeli Security Agency (ISA) apply sophisticated means of torture in interrogations to gain information and confessions from those interrogated, most commonly Palestinians from the West Bank, without leaving obvious evidence of physical torture behind. In practice, psychological torture, as well as the long-term psychological effects of all methods of torture, are often overshadowed by medical-legal evidence of physical torture, which is given prominence by the adjudicating bodies. As in other contexts, the scars inflicted on the mind, sense of identity and personality of the victims are often persistent and more harmful than those inflicted on the body according to PCATI's experience. Data from the past five years indicates that sleep deprivation is used in nearly $70 \%$ of PCATI's cases involving Palestinian detainees interrogated by the ISA (PCATI, 2019). Despite the common use of the method, its impact on the victims had not previously been systematically addressed. 


\section{Objective}

With the aim to develop instruments for the documentation of various psychological torture methods, this article explains our methodology for research-based interdisciplinary instruments and the process of developing the first example of this approach relating to the documentation of sleep deprivation.

\section{Development of the Sleep Deprivation Protocol}

A conference held in Copenhagen in November 2015 highlighted the need among lawyers and health professionals for new tools to improve documentation of psychological torture. As a result, in 2016, DIGNITY - Danish Institute Against Torture, REDRESS and PCATI began a joint project perceived as a vehicle to establish a common understanding between health and legal professionals as to the reasons for the use of psychological torture, its impact, and how to improve the interdisciplinary documentation of such acts. The project aims at developing best practices on documentation of psychological torture; establishing evidence in individual court cases; strengthening jurisprudence and caselaw about psychological torture; and influencing policy debates while promoting better acknowledgement of psychological torture among key stakeholders.

Strategically, it was decided to focus on the target group of lawyers and health professionals who are independent of the state and who often meet and interview victims of torture. Better documentation on their behalf, based on research-informed tools, would lead to the collection of evidence that could be used within the judicial system and in local and international advocacy efforts to raise awareness of the severe consequences of psychological torture and of the temptation among national authorities to use such methods to avoid accountability.

DIGNITY, REDRESS and PCATI set up a project group and an international expert group ${ }^{1}$ who met in London in 2017 and Copenhagen in 2018 to discuss existing medical and legal knowledge with regard to psychological torture methods and the limitations of and common challenges in its documentation. It was agreed to adopt the following methodology for the development of research-based protocols to document psychological torture methods:

1) Review of existing legal and health knowledge regarding the specific method of torture, both in clinical and nontorture contexts;

2) Drafting of an interdisciplinary researchinformed protocol with specific questions;

3) Discussion within the group of international experts;

4) Adjustment of the protocol to a specific local context if required, pilot-testing; and

5) Evaluation.

Each protocol would include specific questions to be asked during an interview with a victim of torture. This approach should address lawyers' requests for more clarity on how to understand the concept of pain and suffering and research-oriented evidence of harms resulting from psychological torture in order to guide the adjudicator when

1 The group includes the following experts and organisations in addition to the authors of this article: Nora Sveaass, Nimisha Patel, Brock Chisholm, Pau Pérez-Sales, Ahmed Benasr, REDRESS (Alejandra Vicente), Freedom from Torture (Angela Burnett and Emily Rowe), IRCT (Asger Kjærum and James Lin), PCATI (Efrat Bergman-Sapir), and University of Essex (Carla Ferstman). 
interpreting the definition of torture in the UN Convention against Torture and Other Cruel, Inhuman or Degrading Treatment or Punishment and the scope of cruel or inhuman and degrading treatment.

The group decided to begin the process with one specific method for in-depth consideration: sleep deprivation, as it is a prevalent method used in interrogation in Israel and elsewhere. The content of the Protocol was developed following the methodology previously mentioned, and bearing in mind that sleep deprivation is often used to obtain information or a confession, albeit unreliable, during an interrogation (Cakal, 2019). The Protocol includes explanations as to the different types of sleep deprivation that are used.

\section{Pilot experience of the Sleep Deprivation Protocol}

\section{Step I - Adapting the Protocol. As a first} step in the piloting process, PCATI adapted four of the Protocol's sections to the local context - Israel in this case. This was done based on PCATI's on-theground experience, bearing in mind the legal framework in Israel, and the reality in which interviews with victims are carried out and affidavits taken. For example, interrogations are often long, commonly lasting between two weeks to a month; interviews with victims are conducted in detention, a few weeks at minimum after the interrogation ended, and in far from ideal settings (e.g. limited time and with a separating glass barrier). The adaptation led to a shorter Protocol that reflects typical interrogation patterns in Israel and enables questions that are more open (professional medical terms were not altered). The four sections were then translated to Hebrew. The translation was reviewed by lawyers who regularly conduct prison visits. It is worthwhile noting that the adaptation and translation process was done in view of creating a practical hands-on legal tool rather than a research protocol.

Step II - Piloting. The Protocol was piloted in seven cases, all involving Palestinians who had been subjected to an ISA interrogation in the previous 12 months. In six of the cases, lawyers visited and interviewed detainees using the Protocol in full. In the seventh case, health professionals - a physician and a psychologist - supplemented an Istanbul Protocol (IP) evaluation with questions from the supplementary Protocol regarding sleep patterns and sequelae. The cases were selected in an effort to reflect existing diversity. Two of the cases were of female detainees who were subjected to psychological torture during interrogation; two cases involved male detainees whose interrogation included mostly psychological torture; and the last two cases involved male detainees subjected to an interrogation that included "enhanced interrogation techniques" (i.e. stress positions and beatings in addition to the psychological torture). All cases included deprivation of sleep, a fact that was known to PCATI beforehand, as the Protocol was piloted only in cases where affidavits had previously been taken and thus rapport established. The six interviews were carried out by female and male lawyers and took place in three different prisons over a period of three months. The IP evaluation was conducted in prison with one of the female detainees who had been interviewed by the lawyers. 
Step III - Evaluation. Each interview and the IP evaluation were analyzed by PCATI based on feedback from the lawyers and health professionals involved, and in light of the quality of the information collected. The information in each Protocol was compared to that captured in affidavits previously taken in the same cases. Follow-up visits were conducted with the six interviewees.

Following the pilot, the lawyers reported that the Protocol improved their way of asking questions during the interview, and they felt more comfortable in asking about intimate issues related to sleep and rest such as re-occurring dreams. The structure of the Protocol enabled them to collect new information; the section exploring the so-called "rest time" was particularly revealing as detainees often experienced a fragmented and insufficient resting period. Interestingly, lawyers were surprised that the interviewees, male and female alike, had hardly any hesitation in talking about their sleep patterns and dreams. Health professionals added some of the questions in the Protocol to their IP evaluation. Additionally, the process of adapting and implementing the Protocol enabled staff and external professionals to better conceptualize what sleep deprivation actually "consists of." Following the pilot-phase, PCATI concluded that the Protocol, which should and will be used in Arabic and in Hebrew, has best impact when not used as a stand-alone tool but as an integrated part of the process of taking testimony from a detainee. It is planned that the revised Protocol will be added to the standard interviewing toolkit for lawyers starting in 2020 .

\section{Conclusion}

DIGNITY, REDRESS and PCATI seek to inform and influence policy debates, and ensure better acknowledgement of psychological methods of torture and ill-treatment. Our study has shown that developing a specific interdisciplinary protocol has improved documentation practices among lawyers working with PCATI. We envisage further pilot-testing of the Sleep Deprivation Protocol in other countries as well as the development of new documentation tools for other methods that build on the Istanbul Protocol, medical and legal knowledge, and field research. We hope that the Protocol(s) will be informed by local practices and used widely in the future.

\section{References}

Cakal, E. (2018). Debility, dependency and dread: On the conceptual and evidentiary dimensions of psychological torture, Torture fournal, 28(2), 1537. doi.org/10.7146/torture.v28i2.106908

Cakal, E. (2019). Befogging Reason, Undermining Will: Understanding Sleep Deprivation as Torture and Other Ill-Treatment in International Law. Torture fournal 29(2), 11-22. doi:https://10.7146/ torture.v29i2.109620

PCATI (2019). Torture in Israel, Situation Report 2019. Retrieved from http://stoptorture.org.il/ publications/studies/?lang=en

PCATI (2016). Shadow Report to the UN Committee against Torture towards the review of the fifth periodic report on Israel. Retrieved from https://tbinternet.ohchr. org/_layouts/15/TreatyBodyExternal/Countries. aspx? CountryCode $=$ ISR \&Lang $=\mathrm{EN}$

Pérez-Sales, P. (2017). Psychological Torture: Definition, Evaluation and Measurement. London: Routledge. doi. org/10.4324/9781315616940

Rejali, D. (2007). Torture and Democracy. Princeton, NJ: Princeton University Press.

UN Office of the High Commissioner for Human Rights (OHCHR). (2004). Manual on the Effective Investigation and Documentation of Torture and Other Cruel, Inhuman or Degrading Treatment of Punishment ("Istanbul Protocol”). HR/P/PT/8/Rev. 1 